Journal of Research in Interprofessional

Practice and

Education

Vol. 8.1

2018

\title{
Key Strategies for First-Time Interprofessional Teachers and Those Developing New Interprofessional Education Programs
}

\author{
Eileen McKinlay, MA (App), RN; Louise Beckingsale, MHealSci, NZRD; \\ Sarah Donovan, PhD, BMid; Ben Darlow, PhD, MSportPhysio, BPhty; \\ Peter Gallagher, PhD, RN; Ben Gray, MBHL, MBChB; \\ Hazel Neser, MA,HDipEd; Meredith Perry, PhD, MManipTh, BPhty; \\ Sue Pullon, MPHC, MBChB, University of Otago Wellington \\ Karen Coleman, HDCR, BSc(Hons), Hutt Hospital
}

\begin{abstract}
Background: Evidence that interprofessional education (IPE) leads to better teamwork and improved interprofessional collaboration has created a drive to establish pre-registration IPE health science and social care programs. Yet there is limited guidance available for teachers new to IPE.

Objectives: To provide first-time teachers practical strategies to undertake IPE.

Methods: Strategies developed from experience.

Findings: First-time IPE teachers should: try to join an existing IPE team; observe and collaborate with experienced IPE teachers; contribute to the development of new IPE programs; seek institutional support; undertake IPE evaluation and research; and gain high-level institutional endorsement.

Conclusions: Six strategies are designed to overcome commonly recognized problems and enable first-time teachers to more confidently develop or engage in IPE, thus supporting students to attain skills in interprofessional collaboration.

Keywords: Interprofessional education; Pre-registration; Students; Teachers; Professions; Curricula; Health sciences
\end{abstract}

Journal of Research in Interprofessional Practice and Education (JRIPE)

Vol. 8.1

(C) 2018

doi: $10.22230 /$ jripe.2018 v8n1a279

Corresponding author: Eileen McKinlay. Email: eileen.mckinlay@otago.ac.nz

\section{Introduction}

Interprofessional education (IPE) actively facilitates pre-registration students from different health and social professions to learn "with, from and about each other, to improve collaboration, and the quality of care and services" [1]. The goal of IPE is to improve the ability of the different professional groups to work collaboratively in health and social care teams with the aim of improving the quality and safety of patient care and ultimately patient health outcomes [2-4].

Increasingly students are offered IPE classes, usually as electives within their uniprofessional health and social schools. However, the majority of their education, even in the same institution, is undertaken in uni-professional classes in separate 
2

Key Strategies for First-Time Interprofessional Teachers

McKinlay, Beckingsale, Donovan, Darlow, Gallagher, Gray, Neser, Perry, Pullon, \& Coleman

Journal of Research in Interprofessional Practice and Education

Vol. 8.1

2018 programs. Hence, both students and teachers rarely interact outside of their professional group.

More specifically, teachers are unlikely to regularly meet colleagues from other professions, teach in each other's programs, or learn about the similarities and differences between each profession and their respective educational approaches. As a consequence, teachers are unlikely to adopt IPE teaching roles without formal preparation. According to IPE principles, IPE teaching is very different from uniprofessional teaching, as the prime focus is to attain interprofessional competencies through intentional interaction [5].

The University of Otago in Wellington, New Zealand, has progressively developed pre-registration health sciences IPE programs. These are mainly classroom-based, but with integrated small-group student activities involving patient home-visits. The programs began with students from dietetics, medicine, and physiotherapy [6]; radiation therapy was subsequently included [7]. More recently, nursing, pharmacy, clinical psychology, occupational therapy, and social work have joined through partnerships with other institutions. The original IPE teaching team members selfselected, and the core group grew as other professions became involved. The current teacher group, called the Wellington Interprofessional Teaching Initiative (WITI), includes academic staff from all of the participating professions and institutions.

This article, drawing upon the IPE literature and the experiences of the founders of WITI, provides guidelines for establishing and sustaining dynamic and innovative IPE. It is intended for the first-time IPE teacher. Although the strategies below are ordered, the processes by which IPE develops are non-linear, interactive, and often opportunistic. There are also many excellent electronic resources available to support development of IPE such as from the Centre for Advancement of Interprofessional Education or the National Centre for Interprofessional Practice and Education.

\section{Strategies}

First-time IPE teachers should try to join an existing IPE team

Interprofessional education is not a solo activity; first-time IPE teachers should aim to join a teaching team, in which enjoyment, humour, and solidarity are pivotal. Interprofessional education teaching teams are characterized by being inclusive, with teachers from different professions actively seeking additional members and valuing new perspectives and skills, acknowledging each as an "equal player" [8].

Incorporating first-time IPE teachers in a team is more difficult than other education endeavours where co-located staff (usually from the same profession) are able to meet easily $[9,10]$. When staff are new to IPE and from different schools, professions, or institutions, meetings and communicating are more challenging. Physically meeting regularly is more important than in similar uni-professional teaching activities in order to establish trust and mutual reliance [11]. Expect planning to take longer as common pedagogical ground and consensus is sought, based on adult-centred (andragogic) learning. Collectively, the adoption of IPE theory and language will assist planning, teaching, and debriefing and overcome the different professional terminologies [12]. 
3

Key Strategies for First-Time Interprofessional Teachers

McKinlay, Beckingsale, Donovan, Darlow, Gallagher, Gray, Neser, Perry, Pullon, \& Coleman

Journal of Research in Interprofessional Practice and Education

Vol. 8.1

2018
Team leadership is important. Ideally the leader should be chosen for individual skills and not their discipline. In the past, participants from particular professions such as medicine have been expected to be the leaders [13]. The distributed leadership model, which utilizes collaboration among teachers, may be a suitable alternative [14].

Medical students and teachers are not always included in IPE programs, but their involvement can bring advantages for all professions and signals that the medical profession values collaborative clinical practice. However, medical students must demonstrate that they are an equal partner in a shared endeavour [15].

\section{First-time IPE teachers should observe and collaborate} with experienced IPE teachers

First-time IPE teachers need a theoretical introduction to IPE, but equally as important, they need to experience how teachers facilitate an IPE class. Although, firsttime IPE teachers are generally confident in teaching profession-specific skills, they will need to learn to teach in an interprofessional way [16]. Team-teaching is an effective strategy as it enables new teachers to observe how interprofessional teaching is structured, how students are best grouped, what activities and questions are used to prompt interaction, and how experienced IPE teachers turn professionally biased student comments or feedback into learning opportunities [8,17]. Most importantly, new IPE teachers learn not to differentiate or stereotype students by professional group but rather to regard the class group as a whole. A side benefit is that team-teaching enables new teachers to quickly become part of the IPE team [9].

When the WITI first began, teachers of all contributing professions facilitated the class groups; however, the model has evolved to having two teachers from different professions allocated to each classroom [6]. Although this approach is time-consuming and teacher-intensive, it allows teachers to informally learn about each other (individually and professionally), to learn from each other's approaches, and to call on the varied skills of particular professions. Importantly, it also enables students to experience teachers of at least two professions working collaboratively. Having a sufficiently large IPE teaching team increases sustainability by allowing rotating teacher involvement depending on availability, including the option to temporarily opt-out if a topic or timing does not suit [18].

First-time IPE teachers can contribute to the development of new IPE programs

As first-time teachers in a newly formed team, WITI piloted different teaching approaches gleaned from the IPE literature as well as drawing from prior experience in delivering IPE postgraduate programs. Where possible, these approaches have been validated by research $[6,7,19,20]$. Program development has been supported by student feedback and by including students on curriculum or IPE planning committees [19,21].

For a new IPE program, it is wise to consider the learning stage of each professional cohort and the numbers of students from each profession [16]. In New Zealand, pre-registration or pre-licensure health sciences and social work programs range from two to six years, depending on the profession, and may be an undergrad- 
4

Key Strategies for First-Time Interprofessional Teachers

McKinlay, Beckingsale, Donovan, Darlow, Gallagher, Gray, Neser, Perry, Pullon, \& Coleman

Journal of Research in Interprofessional Practice and Education

Vol. 8.1

2018 uate or master's degree program. Some professions have very small entrant numbers, and sometimes there is only one student available in the class. Grouping students in IPE programs according to the early, mid, or senior years of their program is important, however it may not always be possible [21]. If students grouped together are at very different stages of skill development, it is best to teach a topic that none have previously studied in depth.

The University of Otago Wellington has integrated IPE within the existing curricula and thus it is compulsory for the students. This means that IPE is considered a usual curricula component and not an optional or extra requirement [22]. Even when IPE is routine, it is important that the different professions value the IPE assessment equally; students quickly sense when it means more to one profession than another [23].

Interprofessional education programs typically include large numbers of students in order to create heterogeneous classes [24]. Forging partnerships with several other institutions may be necessary to include a wider range of professions or counter vastly mismatching profession cohort sizes [25-29]. The time, effort, and persistence needed to form partnerships should not be underestimated. The effort expended, however, produces outcomes that are fruitful and lead to sustainable IPE programs.

Building interaction into IPE programs is essential to encourage students to meet, share information about their professions, and learn how they work together in clinical practice. Within the IPE classes, small interprofessional threesomes are formed comprising students from several professions. Sub-group tasks are carefully developed to facilitate collaboration and working together. Furthermore, embedding social learning activities in IPE programs helps address the professional hierarchies that are sometimes visible in clinical practice [24,30,31]. The following activities have been helpful: class lunches; icebreaker activities; structured time in class to talk informally; travelling to activities as an interprofessional group; outsideof-class learning activities; and the use of a common eLearning platform [32].

\section{First-time IPE teachers should seek institutional support}

First-time (and seasoned) teachers need broad institutional support, as not everyone can be centrally involved in IPE teaching and support from others is critical to progress [16]. It is not always possible to represent every technical skill set in the teaching team, and it is important to seek help for specific activities. For example, it is valuable to involve education advisors to facilitate student and staff focus groups to critique teaching. Student responses may provide data to undertake novel research.

Administrative support is essential for organizing a complex IPE program. An administrator who is dedicated to an IPE program, will by association also develop a comprehensive understanding of IPE. The administrator's role includes resource development, arranging clinical placements and visits, managing eLearning platforms, liaising with all students and teachers, and collating student assignments. Funding such a role can be difficult when IPE straddles different programs and institutions.

Those with key roles in institutions can advocate for solutions and compromises for recognized organizational and attitudinal challenges. These include different 
5

Key Strategies for First-Time Interprofessional

Teachers

McKinlay, Beckingsale, Donovan, Darlow, Gallagher, Gray, Neser, Perry, Pullon, \& Coleman

Journal of Research in Interprofessional Practice and Education

Vol. 8.1

2018 curricula configurations and timetables; variations in assessment requirements; mismatched semester dates; separate faculty accommodation; trade-offs for clinical time; resistance to the introduction of IPE; and unwillingness to become involved $[33,34]$.

First-time IPE teachers are able to undertake IPE evaluation and research Even if an IPE team is solely comprised of first-time teachers, team members should aim to routinely evaluate IPE programs and to explore novel research questions from both student and teacher perspectives [6,7,19,35-37]. Both quantitative and qualitative methods should be employed. Use validated tools to measure change in attitudes, knowledge, and skills [38]. The nominal group qualitative method has proved ideal for larger student or teacher groupings, as it supports the exploration of the subtleties of small program refinements when the same facilitators and question frameworks are used [39]. Detailed records of IPE teacher meetings should be maintained to track the development and decision-making processes. These can also be used as documentary data in evaluation [40].

It is important to publish findings on what works well, what has been less successful, and what was learned from experience, as this contributes to the international body of IPE knowledge. In the spirit of interprofessional collaboration, profile and acknowledge all those directly involved in publications, reports, and conference presentations.

\section{First-time interprofessional teachers and new IPE programs} should gain high-level endorsement

Interprofessional education programs may start spontaneously or may be mandated by institutions $[14,41]$. Either way, there can be a lack of understanding by leaders with difficulties embracing IPE in preference to uni-professional teaching [34]. Firsttime teachers and IPE teacher teams are key champions, and their enthusiasm, vision, and determination can overcome these early challenges [42]. However, as time goes on, high-level governance is essential to endorse IPE as first-time teachers or IPE teaching teams cannot do this on their own $[22,43]$.

Ideally, each institution should allocate appropriate funds for the development, expansion, and payment of teachers and administrators participating in IPE, and provide formal teacher induction programs and resource development [44]. However, institutions are often slow to have dedicated IPE funding and establish workload models and funding for academics involved in IPE programs [23,41]. As an interim measure, teachers may have to initially piece together resources from their own profession's budget although in the long-term, IPE programs cannot be undertaken solely on teacher goodwill [44]. In the WITI team's experience, it was necessary to formally demonstrate the benefits of IPE before the financial resources were committed. Subsequently with the growing momentum for IPE, the University of Otago has established a Health Sciences Centre for Interprofessional Education with funded posts for IPE Regional Campus Leads and dedicated competitive funding to establish IPE pilot programs [45]. 
6

Key Strategies for First-Time Interprofessional Teachers

McKinlay, Beckingsale, Donovan, Darlow, Gallagher, Gray, Neser, Perry, Pullon, \& Coleman

Journal of Research in Interprofessional Practice and Education

Vol. 8.1

2018

\section{Summary}

There is growing support globally to establish health sciences and social care IPE programs to support interprofessional competencies, which increase collaborative clinical practice. However, for this momentum to be sustained, new IPE teachers and programs are needed to deliver an increased volume of teaching. The six strategies described in this article derive from the collective experience of teachers involved in an organic and evolving IPE program. While applicability will partly depend on local context, these strategies address many commonly encountered issues for first-time IPE teachers and new programs, and will help ensure a rich and collegial learning environment for teachers and students alike.

\section{References}

1. Centre for the Advancement of Interprofessional Education. (2017). Interprofessional education. URL: https://www.caipe.org/about-us [December 1, 2018].

2. Reeves, S., Fletcher, S., Barr, H., Birch, I., Boet, S., Davies, N., McFadyen, A., Rivera, J., \& Kitto, S. (2016). A BEME systematic review of the effects of interprofessional education: BEME Guide No. 39. Medical Teacher, 38(7), 656-668. doi: https://doi.org/10.3109/0142159X.2016.1173663

3. Institute of Medicine. (2015). Measuring the impact of interprofessional education on collaborative practice and patient outcomes. URL: https://www.nap.edu/catalog/21726/measuring-theimpact-of-interprofessional-education-on-collaborative-practice-and-patient-outcomes [December 1, 2018].

4. Frenk, J., Chen, L., Bhutta, Z., Cohen, J., Crisp, N., Evans, T., Fineberg, H., Garcia, P., Ke, Y., \& Kelley, P. (2010). Health professionals for a new century: Transforming education to strengthen health systems in an interdependent world. The Lancet, 376(9756), 1923-1958. doi:10.1016/S0140-6736(10)61854-5

5. Canadian Interprofessional Health Collaborative (CIHC). (2010). National interprofessional competency framework. URL: http://www.cihc.ca/files/CIHC_IPCompetencies_Feb1210.pdf [December 1, 2018].

6. Pullon, S., McKinlay, E., Beckingsale, L., Perry, M., Darlow, B., Gray, B., Gallagher, P., Hoare, K., \& Morgan, S. (2013). Interprofessional education for physiotherapy, medical and dietetics students: A pilot programme. Journal of Primary Health Care, 5(1), 52-58. doi:10.1186/s12875-016 $-0417-z$

7. Darlow, B, Coleman, K., McKinlay, E., Donovan, S., Beckingsale, L., Gray, B., Neser, H., Perry, M., Stanley, J., \& Pullon, S. (2015). The positive impact of interprofessional education: a controlled trial to evaluate a programme for health professional students. BMC Medical Education, 15(1), 98. doi: 10.1186/s12909-015-0385-3

8. Steinert, Y. (2005). Learning together to teach together: Interprofessional education and faculty development. Journal of Interprofessional Care, 19(S1), 60-75. doi: https://doi.org/10.1080 $/ 13561820500081778$

9. Hall, L., \& Zierler, B. (2015). Interprofessional education and practice guide No. 1: Developing faculty to effectively facilitate interprofessional education. Journal of Interprofessional Care, 29(1), 3-7. doi: https://www.tandfonline.com/doi/full/10.3109/13561820.2014.937483

10. Carlisle, C., Cooper, H., \& Watkins, C. (2004). "Do none of you talk to each other?": The challenges facing the implementation of interprofessional education. Medical Teacher, 26(6), 545552. doi: $10.1080 / 61421590410001711616$

11. West, C., Graham, L., Palmer, R., Miller, M., Thayer, E., Stuber, M., Awdishu, R.A., Umoren, M.A., Wamsley, \& Nelson, E. (2016). Implementation of interprofessional education (IPE) in 16 US medical schools: Common practices, barriers and facilitators. Journal of Interprofessional Education \& Practice, 4, 41-49. doi: https://doi.org/10.1016/j.xjep.2016.05.002

12. Roberts, C., \& Kumar, K. (2015). Student learning in interprofessional practice-based environments: What does theory say? BMC Medical Education, 15(211), 1-3. doi: 10.1186/s12909-015-0492-1

13. Brewer, M., Flavell, H., Trede, F., \& Smith, M. (2016). A scoping review to understand "leadership" in interprofessional education and practice. Journal of Interprofessional Care, 30(4), 408-415. URL: https://www.tandfonline.com/doi/abs/10.3109/13561820.2016.1150260 [December 1, 2018]. 
7

Key Strategies for First-Time Interprofessional Teachers

McKinlay, Beckingsale, Donovan, Darlow, Gallagher, Gray, Neser, Perry, Pullon, \& Coleman

Journal of Research in Interprofessional Practice and Education

Vol. 8.1

2018
14. Trede, F., Smith, M., \& Brewer, M. (2016). Learning about leadership and collaboration in interprofessional education and practice. In A. Croker, J. Higgs, \& F. Trede (Eds.), Collaborating in healthcare: Reinterpreting therapeutic relationships (pp. 261-268). Rotterdam, NL: Sense Publishers.

15. Meleis, A.I. (2016). Interprofessional education: A summary of reports and barriers to recommendations. Journal of Nursing Scholarship, 48(1), 106-112. doi: https://sigmapubs.onlinelibrary .wiley.com/doi/abs/10.1111/jnu. 12184

16. Willgerodt, M., Abu-Rish Blakeney, E., Brock, D., Liner, D., Murphy, N., \& Zierler, B. (2015). Interprofessional education and practice guide no. 4: Developing and sustaining interprofessional education at an academic health center. Journal of Interprofessional Care, 29(5), 421-425. doi: https://doi.org/10.3109/13561820.2015.1039117

17. Carpenter, J., \& Dickinson, H. (2016). Interprofessional education and training. Bristol, UK: Policy Press.

18. McKinlay, E., Gallagher, P., Gray, L., Wilson, C., \& Pullon, S. (2015). Sixteen months "from square one": The process of forming an interprofessional clinical teaching team. Journal of Research in Interprofessional Practice and Education, 5(2), 1-13. URL: http://www.jripe.org/jripe/index.php /journal/article/view/191_[December 1, 2018].

19. Darlow, B., Donovan, S., Coleman, K., McKinlay, E., Beckingsale, L., Gallagher, P., Gray, B., Neser, H., Perry, M., \& Pullon, S. (2016). What makes an interprofessional education programme meaningful to students? Findings from focus group interviews with students based in New Zealand. Journal of Interprofessional Care, 30(3), 355-361. doi: http://dx.doi.org/10.3109 /13561820.2016.1141189

20. Darlow, B., McKinlay, E., Gallagher, P., Beckingsale, L., Coleman, K., Perry, M., \& Pullon, S. (2017). Building and expanding interprofessional teaching teams. Journal of Primary Health Care, 9(1), 29-33. URL: http://www.publish.csiro.au.wmezproxy.wnmeds.ac.nz/hc/pdf /HC16053 [December 1, 2018].

21. Musser, M., Dipietro, N., Walden, L., Montenery, S., \& Terrell, S. (2016). Development of a novel interprofessional education activity with undergraduate students: Design, assessment, and lessons learned. Health and Interprofessional Practice, 3(1), 2. doi: http://dx.doi.org/10.7710/2159 $-1253.1096$

22. Curran, V., \& Sharpe, D. (2007). A framework for integrating interprofessional education curriculum in the health sciences. Education for Health, 20(3), 93. URL: http:/www.education forhealth.net/text.asp?2007/20/3/93/101601 [December 1, 2018].

23. Lawlis, T., Anson, J., \& Greenfield, D. (2014). Barriers and enablers that influence sustainable interprofessional education: A literature review. Journal of Interprofessional Care, 28(4), 305-310. URL: https://www.tandfonline.com/doi/abs/10.3109/13561820.2014.895977 [December 1, 2018].

24. Olson, R., \& Bialocerkowski, A. (2014). Interprofessional education in allied health: A systematic review. Medical Education, 48(3), 236-246. doi: https://doi.org/10.1111/medu.12290

25. Walshe, C., Caress, A., Chew-Graham, C., \& Todd, C. (2007). Evaluating partnership working: lessons for palliative care. European Journal of Cancer Care, 16(1), 48-54. doi: https://doi.org/10 .1111/j.1365-2354.2006.00702.x

26. Holt, J., Coates, C., Cotterill, D., Eastburn, S., Laxton, J., Mistry, H., \& Young, C. (2010). Identifying common competences in health and social care: An example of multi-institutional and inter-professional working. Nurse Education Today, 30(3), 264-270. URL: http:/www .nurseeducationtoday.com/article/S0260-6917(09)00172-5/abstract [December 1, 2018].

27. Peluso, M., Hafler, J., Sipsma, H., \& Cherlin, E. (2014). Global health education programming as a model for inter-institutional collaboration in interprofessional health education. Journal of Interprofessional Care, 28(4), 371-373. doi: https://doi.org/10.3109/13561820.2014.881789

28. Lujan, J., Stout, R., Meagher, G., Ballesteros, P., Santa Cruz, M., \& Estrada, I. (2011). Partnering to maximize simulation-based learning: Nursing regional interdisciplinary simulation centers. Journal of Professional Nursing, 27(6), e41-e45. URL: https://www.sciencedirect.com/science /article/pii/S8755722311001062 [December 1, 2018].

29. King, S., Drummond, J., Hughes, E., Bookhalter, S., Huffman, D., \& Ansell, D. (2013). An interinstitutional collaboration: Transforming education through interprofessional simulations. Journal of Interprofessional Care, 27(5), 429-431. https://www.tandfonline.com/doi/abs $/ 10.3109 / 13561820.2013 .791260$

30. Ebert, L., Hoffman, K., Levett-Jones, T., \& Gilligan, C. (2014). “They have no idea of what we do or what we know": Australian graduates' perceptions of working in a health care team. Nurse Education in Practice, 14(5), 544-550. doi: 10.1016/j.nepr.2014.06.005

31. Gilligan, C., Outram, S., \& Levett-Jones, T. (2014). Recommendations from recent graduates in medicine, nursing and pharmacy on improving interprofessional education in university programs: A qualitative study. BMC Medical Education, 14(1), 52. doi: 10.1186/1472-6920-1114-1152 
8

Key Strategies for First-Time Interprofessional Teachers

McKinlay, Beckingsale, Donovan, Darlow, Gallagher, Gray, Neser, Perry, Pullon, \& Coleman
32. McKinlay, E., Gallagher, P., Wilson, C., Gray, L., McHugh, P., \& Pullon, S. (2016). Social learning, shared accommodation and interprofessional education: I think those conversations that you have at the dinner table ... Journal of Interprofessional Education and Practice, 5, 1-6. URL: https://www.sciencedirect.com/science/article/pii/S2405452616300519 [December 1, 2018].

33. Brommelsiek, M., \& Peterson, J. (2015). Negotiating challenges in community-based interprofessional education programs. Health and Interprofessional Practice, 2(3), 1-8. URL: https://commons.pacificu.edu/cgi/viewcontent.cgi?article=1084\&context=hip [December 1, 2018].

34. Dumont, S., Briere, N., Morin, D., Houle, N., \& Iloko-Fundi, M. (2010). Implementing an interfaculty series of courses on interprofessional collaboration in prelicensure health science curriculums. Education for Health, 23(1), 1-12, eP1084. URL: http://www.educationforhealth.net /text.asp?2010/23/1/395/101499 [December 1, 2018].

35. Coleman, K., Darlow, B., McKinlay, E., Beckingsale, L., Donovan, S., Stanley, J., Gallagher, P., Gray, B., Neser, H., Perry, M., \& Pullon, S. (2014). Does interprofessional education make a difference to students' attitudes to practice? Journal of Medical Imaging \& Radiation Sciences, 45(4), 344-345. doi: https://doi.org/10.1016/j.jmir.2014.10.004

36. Perry, M., Darlow, B., Donovan, S., McKinlay, E., Coleman, K., Beckingsale, L., Gray, B., Pullon, S., Gallagher, P., \& Neser, H. (2015). "We're here for the patient at the end of the day": Perceptions of an IPE programme in long-term conditions management. Physiotherapy, 101, e1195-e1196. doi: https://doi.org/10.1016/j.physio.2015.03.2121

37. Pullon, S., Darlow, B., \& McKinlay., E. (2016). Building evaluation into the development of interprofessional education initiatives. In D. Forman, M. Jones, \& J. Thistlethwaite (Eds.), Leading research and evaluation in interprofessional education and collaborative practice (pp. 145-166). London, UK: Palgrave Macmillan UK.

38. Oates, M., \& Davidson, M. (2015). A critical appraisal of instruments to measure outcomes of interprofessional education. Medical Education, 49(4), 386-398. URL: https://pdfs.semantic scholar.org/9b7d/01f83aa9c6c540bd6fae2f9f1ae469349e16.pdf [December 1, 2018].

39. Harvey, N., \& Holmes, C. A. (2012). Nominal group technique: An effective method for obtaining group consensus. International Journal of Nursing Practice, 18(2), 188-194. doi: https://online library.wiley.com/doi/abs/10.1111/j.1440-172X.2012.02017.x

40. Reeves, S., \& Barr, H. (2016). Twelve steps to evaluating interprofessional education. Journal of Taibah University Medical Sciences, 11(6), 601-605. URL: https://www.sciencedirect.com/science /article/pii/S1658361216301238 [December 1, 2018].

41. Bishop, W. (2016). Integrating IPE into an academic health sciences center: A bottom-up and topdown approach. International Journal of Health Sciences Education, 3(2), 1-7. URL: http://dc.etsu.edu/ijhse/vol3/iss2/2 [December 1, 2018].

42. Ratka, A. (2013). Transition of pharmacy educators to faculty champions of interprofessional education. American Journal of Pharmaceutical Education, 77(7), 1-2.

43. Farnsworth, T.J., Peterson, T., Neill, K., Neill, M., \& Lawson, J. (2015). Understanding the structural, human resource, political, and symbolic dimensions of implementing and sustaining interprofessional education. Journal of Allied Health, 44(3), 152-157. URL: https://www.ingenta connect.com/content/asahp/jah/2015/00000044/00000003/art00006 [December 1, 2018].

44. Kirch, D.G., \& Ast, C. (2015). Interprofessionalism: Educating to meet patient needs. Anatomical Sciences Education, 8(4), 296-298. doi:10.1002/ase.1504

45. University of Otago Division of Health Sciences Centre for Interprofessional Education. (2016). IPE strategy and IPE centre. URL: https://www.otago.ac.nz/healthsciences/staff/ipe/otago 087119.html [December 1, 2018].
Journal of Research in Interprofessional Practice and Education

Vol. 8.1

2018 